\title{
The relationship between diabetic retinopathy and psychosocial functioning: a systematic review
}

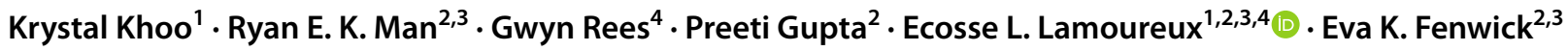

Accepted: 6 March 2019 / Published online: 16 March 2019

(c) Springer Nature Switzerland AG 2019

\begin{abstract}
Importance Previous work has reported a link between diabetic retinopathy/diabetic macular edema (DR/DME) and psychosocial functioning, although the extent and direction of the association remains uncertain.

Objective To determine the relationship between DR/DME and psychosocial functioning, the latter an umbrella term used to capture the emotional and social aspects of functioning which may include, for example, depression; depressive disorder; anxiety; vision-specific distress; diabetes-specific distress and emotional and social well-being.

Evidence review PubMed, Embase, Medline and the Cochrane Central register were systematically searched for relevant interventional and observational quantitative studies using standardised criteria. Studies with DR/DME and psychosocial functioning as exposures or outcomes were accepted. Study quality was evaluated using the modified Newcastle-Ottawa scale for observational studies, and the modified Down's and Black checklist for interventional studies.

Findings Of 1827 titles initially identified, 42 were included in the systematic review. They comprised of four interventions (one RCT, three non-RCTs) and 38 observational studies (33 cross sectional, five prospective). In studies with DR/DME as the exposure $(n=28)$, its severity and related vision impairment were consistently associated with poor psychosocial outcomes, mostly higher incidence of depression and depressive symptoms. Baseline depression and depressive symptoms were also associated with greater DR incidence and progression of DR. Medical intervention strategies showed significant improvement in psychosocial outcomes in patients with DR, such as significant improvements in mental health domain scores of the National Eye Institute Visual Function Questionnaire-25 (NEI VFQ 25).

Conclusion and relevance Severity of DR, DME and associated vision loss are significantly associated with poor psychosocial outcomes. Aspects of depression and its symptoms show a bi-directional association, with increased incidence and progression of DR significant in those with baseline depression or depressive symptoms. Based on these findings, we propose two areas that may benefit from targeted interventions: (1) Prevention of development of poor psychological outcomes by preventing and delaying progression of DR/DME; and (2) Improved detection and management of poor psychological functioning by improving screening tools and multidisciplinary care for patients. Subsequent longitudinal studies can further help establish the underlying relationship between the two measures.
\end{abstract}

Keywords Diabetic retinopathy $\cdot$ Depression $\cdot$ Quality of life $\cdot$ Vision impairment $\cdot$ Psychosocial

Electronic supplementary material The online version of this article (https://doi.org/10.1007/s11136-019-02165-1) contains supplementary material, which is available to authorized users.

Ecosse L. Lamoureux

ecosse.lamoureux@seri.com.sg

1 Yong Loo Lin School of Medicine, National University of Singapore, Singapore, Singapore

2 Singapore Eye Research Institute (SERI), The Academia, 20 College Road, Level 6, Singapore 169856, Singapore
Diabetic retinopathy (DR) and diabetic macular edema (DME) are two of the leading causes of vision loss in adults [1]. An estimated one-third of people with diabetes worldwide have signs of DR, and approximately one in ten will

3 Duke-National University of Singapore Medical School, Singapore, Singapore

4 Centre for Eye Research Australia, Royal Victorian Eye and Ear Hospital, University of Melbourne, Melbourne, Australia 
develop vision-threatening diabetic retinopathy (VTDR), which includes severe non-proliferative DR (NPDR), proliferative DR (PDR) and/or clinically significant macular edema (CSME) [2].

DR and DME have a profoundly detrimental impact on vision-specific functioning [3] (i.e. reading and driving), mobility and independence and quality of life (QoL), [4] particularly in the VTDR stage [3,5]. However, the association between DR and DME with psychosocial outcomes such as depression and anxiety is less well understood [6]. Qualitative work suggests that DR has a considerable emotional impact, resulting in feelings of distress, anger, anxiety and low mood [5, 7]. However, studies exploring the quantitative impact of DR on these psychosocial aspects are more limited $[8,9]$. In this paper, we have used the term "psychosocial" as an umbrella term to capture a wide range of potential psychosocial factors including depression, depressive disorder, anxiety, vision-specific distress, diabetes-specific distress and emotional and social well-being.

A meta-analysis by de Groot and associates in 2001 showed a significant association between complications of diabetes and depression. In particular, ten out of 27 cross-sectional studies included in the analysis showed a significant correlation (combined $p$ value of $<0.001$ ) between DR and depressive symptoms [10]. Similarly, Fenwick and colleagues in 2011 reported that DR and associated visual loss were independently associated with poor emotional well-being [11]. Recently, several quantitative studies have demonstrated an association between DR and poor psychosocial outcomes [9, 12-14]. Others have shown that depression is associated with the presence and incidence of DR [15-19], whereby several pathophysiological mechanisms associated with depression (e.g. alteration in insulin and glucose resistance, dysregulation of the hypothalamic-pituitary-adrenal (HPA) axis and increase in circulating cytokines) have been proposed to play contributory roles in DR pathogenesis. This highlights a plausible bi-directional relationship between DR and psychosocial functioning.

With diabetes reaching epidemic proportions, the prevalence and incidence rates of DR/DME are increasing [2, 20]. A more comprehensive understanding of the relationship between DR/DME and psychosocial outcomes is therefore required so that effective interventions for patients can be developed and implemented. Therefore, this systematic review aims to determine the relationship between DR/DME and psychosocial functioning.

\section{Methods}

\section{Literature search}

A systematic review of current literature was conducted. Four databases, including PubMed, Medline, Embase and Cochrane library, were searched for articles evaluating the relationship between DR/DME and psychosocial functioning. No limitation was placed on the year of publication, with the earliest paper dating back to 1988, up until September 2017. The following search terms were used: (diabetic retinopathy OR diabetic macular [o]edema OR diabetic eye disease OR diabetic microvascular complications) AND (depression OR depressive disorder OR anxiety OR diabetes-related distress OR vision-specific distress OR diabetes-specific distress OR emotional wellbeing OR quality of life OR mental health OR psychological and social functioning). The reference lists of included articles were searched manually to identify and extract other potentially relevant articles.

\section{Inclusion criteria}

We based our eligibility criteria on the PICOS (population, intervention, comparison, outcomes, study design) framework recommended by the Preferred Reporting Items for Systematic Reviews and Meta-Analyses (PRISMA) guidelines (Supplementary Table 1) [21]:

(1) Population Studies involving human participants with either type 1 or type 2 diabetes were included.

(2) Intervention Both interventional (randomised control trials (RCT) and non-RCTs) and observational (cross sectional, case-control and prospective) studies were included.

(3) Comparison Those without DR/DME and without psychological issues

(4) Outcomes The outcomes were the level of psychosocial functioning measured by the use of validated questionnaires or via clinical diagnosis using the Diagnostic and Statistical Manual for Mental Disorders (DSM-IV). In several of the studies, the outcome was the prevalence, severity, incidence or progression of DR/DME

(5) Study design Quantitative

(6) Exposures The exposure was clinically diagnosed DR/ DME. We accepted studies using different assessment methods, including but not limited to fundus photograph, fundoscopy, direct or indirect ophthalmoscopy, fluorescein angiography, clinicians' diagnosis and hospital clinic notes. We also included studies using different scales to grade DR severity, such as the Early 
Treatment Diabetic Retinopathy Study (ETDRS) scale. In several of the studies, the exposure was psychosocial functioning (depressive symptoms or clinically diagnosed depression, measured by clinical diagnoses using the DSM-IV or by a validated questionnaire (e.g. Hospital Anxiety and Depression Scale, Beck Depression Inventory)).

\section{Exclusion criteria}

The following types of articles were excluded:

(1) Review papers or editorials

(2) Qualitative papers

(3) Non-English papers

(4) Studies with irrelevant exposure and/or outcome measures

(5) Studies using utility instruments to assess psychosocial functioning

(6) Studies that reported results for QoL as a whole without specific results for psychosocial functioning

(7) Studies assessing psychosocial outcomes of diabetic complications without specific and separate results for DR/DME

\section{Quality of evidence assessment}

The quality of observational studies was assessed using a modified version of the Newcastle-Ottawa Scale (NOS) [22]. Originally designed to assess prospective and case-control studies, an adapted version of the NOS was used in the current study for the assessment of cross-sectional studies [23]. The NOS uses three main bias-reducing criteria at the study level to award up to a maximum of nine stars: (a) the selection and representativeness of the participants (maximum of four stars), (b) the comparability of groups (maximum of two stars) and (c) the ascertainment of exposure (for case-control) or outcome (for prospective and cross sectional) (maximum of three stars). Following previous reviews, studies assigned $0-4,5-7$ and $\geq 8$ stars were considered as low, medium and high quality, respectively [24].

For the evaluation of interventional studies (non-RCT and RCT), the modified Downs and Black Checklist [25] was used, which measures the risk of bias at the study level via 27 criteria, giving a maximum score of 28 points. The domains covered included reporting, external validity, internal validity and assessment of statistical methods. The total points for each article were then divided by the total possible points-a score of 1 represents the highest possible quality article.

\section{Sensitivity analysis}

In order to ensure that study quality did not influence the outcomes of this systematic review, we conducted a sensitivity analysis. This involved analysing and synthesising the outcomes of the 20 studies rated as "high quality" by the NOS and the two studies rated as high quality by the modified Downs and Black Checklist.

\section{Data extraction}

The following relevant data were extracted from each article reviewed based on the "Strengthening the Reporting of Observational Studies in Epidemiology" (STROBE) statement [26]: year, author, study design, sample size (both diabetes and DR), exposure and outcome measures assessed and method of assessment, adjustments of confounders in analyses, patients' diabetes type and a summary of the pertinent findings. (Tables 3, 4).

\section{Results}

\section{Study characteristics}

Of the 1827 screened titles, 179 were assessed for eligibility. After excluding 136 articles that did not meet the inclusion criteria, 42 were included in the systematic review (Supplementary Fig. 1). They comprised of four interventional (1 RCT and 3 non-RCTs) and 38 observational studies (33 cross sectional and five prospective). A summary of the data extracted from the 42 studies is presented in Tables 3 and 4 .

\section{Measurement of exposures and outcomes}

For the measurement of psychosocial outcome/exposure, most studies $(n=20,47.6 \%)$ utilised questionnaires that assessed generic health-related QoL with specific analyses on psychosocial outcomes (e.g. the Mental Health Composite Score (MCS) of the Short Form instruments [SF$12(n=4,9.52 \%)$, SF-36 $(n=3,7.14 \%)]$, VRQoL (e.g. the National Eye Institute Visual Functioning Questionnaire (NEI VFQ)-25 $(n=10,23.8 \%))$ or depression (e.g. Patient Health Questionnaire-9 (PHQ-9) $(n=3,7.14 \%))$ from the patient's perspective. Two studies measured depression or depressive symptoms clinically using the Diagnostic and Statistical Manual for Mental Disordered (DSM).

DR was assessed using fundus photographs (number of fields unspecified; $n=3$ ), seven-field fundus photography $(n=6)$, stereoscopic fundus photography $(n=1)$, four-field stereo retinal colour photography $(n=1)$, two-field colour fundus photography $(n=3)$, ophthalmologist examination $(n=11)$, record linkage $(n=5)$ and symptomatic eye 
problems $(n=1)$. Five studies did not specify the method of DR measurement.

\section{Methodological quality}

Of the 38 observational studies, the majority (92\%) had moderate to high NOS scores, with 20 classified as "high quality" ( $\geq 8$ stars) and 15 as "moderate quality" (5-7 stars). The remaining three studies were classified as "poor quality" ( $\leq 4$ stars) (Table 1$)$. Of the four interventional studies (both RCT and non-RCT) (Table 2), two studies were classified as "high quality" $(\geq 0.8)$ and two as "moderate quality" $(0.5-0.79)$.

\section{Associations between DR (exposure) and psychosocial functioning}

DR and poor psychosocial functioning was significantly associated in 20 of 28 observational studies (Table 3). Of these, eight cross-sectional studies found a significant association between the presence of DR and poor psychosocial functioning, [12, 27-34] including greater odds of depression, depressive symptoms and anxiety. For instance, Le Floch and colleagues showed that compared to no DR, any DR was associated with a higher risk of depressive symptoms, defined by a score of $>0$ on the Mini Geriatric Depression Scale $(p<0.05)$ [12]. Of the eight studies, five adjusted for important demographic and clinical variables such as Haemoglobin A1c (HbA1c), duration of diabetes and lipid levels [12, 28-30].

Eight other cross-sectional studies found that severe DR, compared to early stage or no DR, was significantly associated with worse psychosocial outcomes. Mazhar and associates found that the decline in scores on the mental health domains of the NEI VFQ-25 and the SF-12 was modest until severity reached moderate NPDR in at least one eye, after which the decline in mental health became significantly steeper [35]. The remaining four studies evaluated the association between DR-associated vision loss and psychosocial outcomes [14, 32, 36, 37], with three studies reporting a significant link between reduced visual acuity (VA) and poor vision in the better eye with significantly impaired psychosocial functioning [32, 36, 37]. However, Fenwick and colleagues found, in path analyses of 514 patients with DR using DR-specific item banks, that the relationship between self-reported visual symptoms and emotional distress was mediated by mobility, inconvenience, activity limitation and social restriction $(p<0.05)$ [14].

Eight cross-sectional studies using mental health subscale scores from various QoL or depression questionnaires reported non-significant associations between DR and psychosocial functioning, [38-44] suggesting that the relationship between psychosocial functioning and DR may be driven by other medical or sociodemographic factors. Hirai and colleagues initially found, in univariate analysis, that compared to those with less severe DR and no visual impairment, a higher proportion of individuals with depression was observed among those with more severe DR and visual impairment. These associations attenuated in multivariable analyses, [38] with employment status (i.e. being unemployed vs employed) emerging as the main factor affecting MCS score.

\section{Associations between depression (exposure) and DR}

Current evidence for the bi-directional relationship between poor psychosocial outcomes and DR was limited to depression, with no studies reporting other aspects of psychosocial functioning (e.g. anxiety, emotional well-being). Of the ten relevant studies, [16-19, 45-48] six cross-sectional and three longitudinal studies found a significant, independent association between depression and DR. In the three longitudinal studies, antecedent clinical depression, [48] more severe depression and presence of depression at baseline [18] independently increased the risk of both DR incidence and progression, independent of glycemic control [18] and other health behaviours such as smoking, physical activity and diet [17-20, 46-48].

Roy and colleagues [18] found that type 1 DM patients with high Beck Depression Inventory (BDI) scores at both baseline and 6-year follow-up visits were more likely to show progression of DR (OR 2.44; 95\% CI 1.01-5.88; $p=0.049$ ) and progression to PDR (OR 3.19; 95\% CI $1.30-7.87 ; p=0.01)$ at follow-up than patients with low BDI scores. Similarly, Sieu and associates [19] showed that severe depression at baseline was associated with an independent increased risk of incident DR in patients with type 2 DM [OR 1.03; 95\% CI 1.00-1.05] as well as shortened time to incident DR (hazard ratio $=1.03 ; 95 \%$ CI 1.01-1.04). The risk of incident DR was estimated to increase by up to $15 \%$ for every significant increase in depressive symptoms severity (5-point increase on the PHQ-9). Also, in patients with type 2 DM and depression, Yekta and co-workers [15] reported that individuals using antidepressants were less likely to have DR (OR $0.50,95 \%$ CI: $0.31-0.82, p<0.05$ ) compared to those who were not. Only one study did not find any significant association between depressive symptoms and DR; [49] however, this was a small, unadjusted, crosssectional study where details of the fundus examination were not well specified.

\section{Medical interventions for DR on psychosocial functioning}

Three studies explored the impact of medical interventions for DR on psychosocial functioning (Table 4). Loftus and 
Table 1 Ratings of articles reviewed

\begin{tabular}{|c|c|c|c|c|}
\hline Author and year & Study design & Study title & $\begin{array}{l}\text { Newcastle-Ottawa } \\
\text { scale (maximum } 10 \\
\text { stars) }\end{array}$ & $\begin{array}{l}\text { Quality of article ( } 0-4 \text { : } \\
\text { low, 5-7: medium, } \geq 8 \text { : } \\
\text { high) }\end{array}$ \\
\hline \multicolumn{5}{|c|}{ Diabetic retinopathy (DR) has a negative impact on psychological outcomes } \\
\hline Miyaoka (1997) & Cross sectional & $\begin{array}{l}\text { Impact of sociodemographic and } \\
\text { diabetes-related characteristics on } \\
\text { depressive state among non-insulin- } \\
\text { dependent diabetic patients }\end{array}$ & 5 & Medium \\
\hline Roy (2001) & Cross sectional & $\begin{array}{l}\text { Depressive symptoms in African Ameri- } \\
\text { can type } 1 \text { diabetics }\end{array}$ & 10 & High \\
\hline Davidov (2009) & Cross sectional & $\begin{array}{l}\text { Diabetic retinopathy and health-related } \\
\text { quality of life }\end{array}$ & 8 & High \\
\hline Pouwer (2010) & Cross sectional & $\begin{array}{l}\text { Prevalence of comorbid depression is } \\
\text { high in out-patients with type } 1 \text { or type } \\
2 \text { diabetes mellitus. Results from three } \\
\text { out-patient clinics in the Netherlands }\end{array}$ & 9 & High \\
\hline Mazhar (2011) & Cross sectional & $\begin{array}{l}\text { Severity of diabetic retinopathy and } \\
\text { health-related quality of life: the Los } \\
\text { Angeles Latino Eye Study }\end{array}$ & 10 & High \\
\hline Poongothai (2011) & Cross sectional & $\begin{array}{l}\text { Association of depression with compli- } \\
\text { cations of type } 2 \text { diabetes-the Chennai } \\
\text { Urban Rural Epidemiology Study } \\
\text { (CURES-102) }\end{array}$ & 10 & High \\
\hline Öztürk (2013) & Cross sectional & $\begin{array}{l}\text { Association of depression and sleep } \\
\text { quality with complications of type } 2 \\
\text { diabetes in elderly }\end{array}$ & 8 & High \\
\hline Trento (2013) & Cross sectional & $\begin{array}{l}\text { Quality of life, impaired vision and } \\
\text { social role in people with diabetes: a } \\
\text { multicentre observational study }\end{array}$ & 6 & Medium \\
\hline $\begin{array}{l}\text { Malgorzata Gorska- } \\
\text { Ciebiada (2014) }\end{array}$ & Cross sectional & $\begin{array}{l}\text { Mild cognitive impairment and depres- } \\
\text { sive symptoms in elderly patients with } \\
\text { diabetes: prevalence, risk factors and } \\
\text { comorbidity }\end{array}$ & 7 & Medium \\
\hline Kalantari (2014) & Cross sectional & $\begin{array}{l}\text { Association of depression with type } 2 \\
\text { diabetes and relevant factors }\end{array}$ & 5 & Medium \\
\hline Le Floch (2014) & Cross sectional & $\begin{array}{l}\text { Retinopathy, nephropathy, peripheral } \\
\text { neuropathy and geriatric scale scores } \\
\text { in elderly people with type } 2 \text { diabetes }\end{array}$ & 9 & High \\
\hline Chinmay (2015) & Cross sectional & $\begin{array}{l}\text { Correlation between types of diabetic } \\
\text { retinopathy and its psychosocial } \\
\text { impact }\end{array}$ & 4 & Low \\
\hline $\mathrm{Xu}(2015)$ & Cross sectional & $\begin{array}{l}\text { Investigating factors associated with } \\
\text { depression of type } 2 \text { diabetic retinopa- } \\
\text { thy patients in China }\end{array}$ & 8 & High \\
\hline Ratanasukon (2016) & Cross sectional & $\begin{array}{l}\text { The Impact of Vision Impairment (IVI) } \\
\text { Questionnaire; validation of the Thai } \\
\text { Version and the implementation on } \\
\text { Vision-related quality of life in Thai } \\
\text { rural community }\end{array}$ & 4 & Low \\
\hline Trento (2016) & Cross sectional & $\begin{array}{l}\text { Vision-related quality of life in patients } \\
\text { with type } 2 \text { diabetes in the EURO- } \\
\text { CONDOR trial }\end{array}$ & 9 & High \\
\hline Rajput (2016) & Cross sectional & $\begin{array}{l}\text { Prevalence and predictors of depression } \\
\text { and anxiety in patients of diabetes } \\
\text { mellitus in a tertiary care centre }\end{array}$ & 6 & Medium \\
\hline Rees (2016) & Cross sectional & $\begin{array}{l}\text { Association between diabetes-related } \\
\text { eye complications and symptoms of } \\
\text { anxiety and depression }\end{array}$ & 9 & High \\
\hline
\end{tabular}


Table 1 (continued)

\begin{tabular}{|c|c|c|c|c|}
\hline Author and year & Study design & Study title & $\begin{array}{l}\text { Newcastle-Ottawa } \\
\text { scale (maximum } 10 \\
\text { stars) }\end{array}$ & $\begin{array}{l}\text { Quality of article }(0-4 \text { : } \\
\text { low, 5-7: medium, } \geq 8 \text { : } \\
\text { high) }\end{array}$ \\
\hline Pereira (2017) & Cross sectional & $\begin{array}{l}\text { Quality of life in people with diabetic } \\
\text { retinopathy: Indian study }\end{array}$ & 7 & Medium \\
\hline Fenwick (2017) & Cross sectional & $\begin{array}{l}\text { Inter-relationship between visual symp- } \\
\text { toms, activity limitation and psycho- } \\
\text { logical functioning in patients with } \\
\text { diabetic retinopathy }\end{array}$ & 9 & High \\
\hline Matza (2008) & Observational; prospective & $\begin{array}{l}\text { The longitudinal link between visual } \\
\text { acuity and health-related quality of life } \\
\text { in patients with diabetic retinopathy }\end{array}$ & 7 & Medium \\
\hline \multicolumn{5}{|c|}{ No association between diabetic retinopathy and psychological outcomes } \\
\hline Karlson (1997) & Cross sectional & $\begin{array}{l}\text { Burden of illness, metabolic control and } \\
\text { complications in relation to depressive } \\
\text { symptoms in IDDM patients }\end{array}$ & 7 & Medium \\
\hline Esteban (2008) & Cross sectional & $\begin{array}{l}\text { Visual impairment and quality of life: } \\
\text { gender differences in the elderly in } \\
\text { Cuenca, Spain }\end{array}$ & 10 & High \\
\hline Lee (2009) & Cross sectional & $\begin{array}{l}\text { Depression, quality of life and glycemic } \\
\text { control in individuals with type } 2 \\
\text { diabetes }\end{array}$ & 6 & Medium \\
\hline Iype (2009) & Cross sectional & $\begin{array}{l}\text { Cognition in type } 2 \text { diabetes: association } \\
\text { with vascular risk factors, complica- } \\
\text { tions of diabetes and depression }\end{array}$ & 5 & Medium \\
\hline Hirai (2012) & Cross sectional & $\begin{array}{l}\text { Relationship between retinopathy sever- } \\
\text { ity, visual impairment and depression } \\
\text { in persons with long-term type } 1 \\
\text { diabetes }\end{array}$ & 10 & High \\
\hline Granstrom (2015) & Cross sectional & $\begin{array}{l}\text { Visual functioning and health-related } \\
\text { quality of life in diabetic patients } \\
\text { about to undergo anti-vascular } \\
\text { endothelial growth factor treatment for } \\
\text { sight-threatening macular edema }\end{array}$ & 6 & Medium \\
\hline Das (2016) & Cross sectional & $\begin{array}{l}\text { Changing clinical presentation, current } \\
\text { knowledge-attitude-practice and cur- } \\
\text { rent vision-related quality of life in } \\
\text { self-reported type } 2 \text { diabetes patients } \\
\text { with retinopathy in Eastern India: the } \\
\text { LVPEI Eye and Diabetes Study }\end{array}$ & 5 & Medium \\
\hline Hirai (2013) & Observational; prospective & $\begin{array}{l}\text { Ten-year change in self-rated quality of } \\
\text { life in a type } 1 \text { diabetes population: } \\
\text { Wisconsin Epidemiologic Study of } \\
\text { Diabetic Retinopathy }\end{array}$ & 9 & High \\
\hline \multicolumn{5}{|c|}{ Association between depression and diabetic retinopathy } \\
\hline Cohen (1997) & Cross sectional & $\begin{array}{l}\text { The association of lifetime psychiatric } \\
\text { illness and increased retinopathy in } \\
\text { patients with type I diabetes mellitus }\end{array}$ & 7 & Medium \\
\hline Black (1999) & Cross sectional & $\begin{array}{l}\text { Increased health burden associated with } \\
\text { comorbid depression in older diabetic } \\
\text { Mexican Americans. Results from the } \\
\text { hispanic-established population for } \\
\text { the epidemiologic study of the elderly } \\
\text { survey }\end{array}$ & 9 & High \\
\hline Al-Ghamdi (2004) & Cross sectional & $\begin{array}{l}\text { A high prevalence of depression among } \\
\text { diabetic patients at a teaching hospital } \\
\text { in Western Saudi Arabia }\end{array}$ & 6 & Medium \\
\hline
\end{tabular}


Table 1 (continued)

\begin{tabular}{|c|c|c|c|c|}
\hline Author and year & Study design & Study title & $\begin{array}{l}\text { Newcastle-Ottawa } \\
\text { scale (maximum } 10 \\
\text { stars) }\end{array}$ & $\begin{array}{l}\text { Quality of article }(0-4 \text { : } \\
\text { low, 5-7: medium, } \geq 8 \text { : } \\
\text { high) }\end{array}$ \\
\hline Bajaj (2012) & Cross sectional & $\begin{array}{l}\text { Association of depression and its } \\
\text { relation with complications in newly } \\
\text { diagnosed type } 2 \text { diabetes }\end{array}$ & 3 & Low \\
\hline Ali (2013) & Cross sectional & $\begin{array}{l}\text { Prevalence of depression among type } \\
2 \text { diabetes compared to healthy non- } \\
\text { diabetic controls }\end{array}$ & 5 & Medium \\
\hline Yekta (2015) & Cross sectional & $\begin{array}{l}\text { The association of antidepressant } \\
\text { medications and diabetic retinopathy } \\
\text { among people with diabetes }\end{array}$ & 8 & High \\
\hline Ishizawa (2016) & Cross sectional & $\begin{array}{l}\text { The relationship between depressive } \\
\text { symptoms and diabetic complica- } \\
\text { tions in elderly patients with diabetes: } \\
\text { Analysis using the diabetes study from } \\
\text { the Center of Tokyo Women's Medical } \\
\text { University (DIACET) }\end{array}$ & 8 & High \\
\hline Kovacs (1995) & Observational; prospective & $\begin{array}{l}\text { Biomedical and psychiatric risk factors } \\
\text { for retinopathy among children with } \\
\text { IDDM }\end{array}$ & 6 & Medium \\
\hline Roy (2007) & Observational; prospective & $\begin{array}{l}\text { Depression is a risk factor for poor gly- } \\
\text { cemic control and retinopathy in Afri- } \\
\text { can Americans with type } 1 \text { diabetes }\end{array}$ & 9 & High \\
\hline Sieu (2011) & Observational; prospective & $\begin{array}{l}\text { Depression and incident diabetic retin- } \\
\text { opathy: a prospective cohort study }\end{array}$ & 9 & High \\
\hline
\end{tabular}

Table 2 Summary of data extracted from four studies looking at the impact of treatment therapies on psychological outcomes in patients with DR

\begin{tabular}{|c|c|c|c|c|}
\hline Author and year & Study design & Study title & $\begin{array}{l}\text { Modified downs and black checklist } \\
\text { (maximum } 28 \text { point, max score 1) }\end{array}$ & $\begin{array}{l}\text { Quality of article } \\
(0.5-0.79: \text { moderate, } \\
\geq 0.8: \text { high })\end{array}$ \\
\hline Loftus (2011) & $\begin{array}{l}\text { Interventional Rand- } \\
\text { omized Controlled } \\
\text { Trial (RCT) }\end{array}$ & $\begin{array}{l}\text { Changes in vision- and health- } \\
\text { related quality of life in patients } \\
\text { with diabetic macular edema } \\
\text { treated with pegaptanib sodium or } \\
\text { sham (discussion) }\end{array}$ & $\begin{array}{l}\text { 24/28 } \\
\text { Score: } 0.857\end{array}$ & High \\
\hline Yu (2013) & Interventional non-RCT & $\begin{array}{l}\text { Quality of life and emotional } \\
\text { change for middle-aged and } \\
\text { elderly patients with diabetic } \\
\text { retinopathy }\end{array}$ & $\begin{array}{l}\text { 19/28 } \\
\text { Score: } 0.678\end{array}$ & Moderate \\
\hline Turkoglu (2015) & Interventional non-RCT & $\begin{array}{l}\text { Changes in vision-related quality } \\
\text { of life in patients with diabetic } \\
\text { macular edema: ranibizumab or } \\
\text { laser treatment? }\end{array}$ & $\begin{array}{l}24 / 28 \\
\text { Score: } 0.857\end{array}$ & High \\
\hline Granstrom (2016) & Interventional non-RCT & $\begin{array}{l}\text { Patient-reported outcomes and } \\
\text { visual acuity after } 12 \text { months of } \\
\text { anti-VEGF-treatment for sight- } \\
\text { threatening diabetic macular } \\
\text { edema in a real-world setting }\end{array}$ & $\begin{array}{l}18 / 28 \\
\text { Score: } 0.64\end{array}$ & Moderate \\
\hline
\end{tabular}

colleagues [50] compared the effect on psychosocial outcomes of an intravitreal pegaptanib sodium injection to a sham injection in patients with DME and reported a clinically meaningful improvement in the mental health domain of the NEI VFQ-25 after week 102 of pegaptanib treatment $(p<0.05)$, with a concomitant statistically significant improvement in VA (6.1 letters with pegaptanib vs. 1.3 letters for sham, $p<0.01)$. Similar results were observed in 


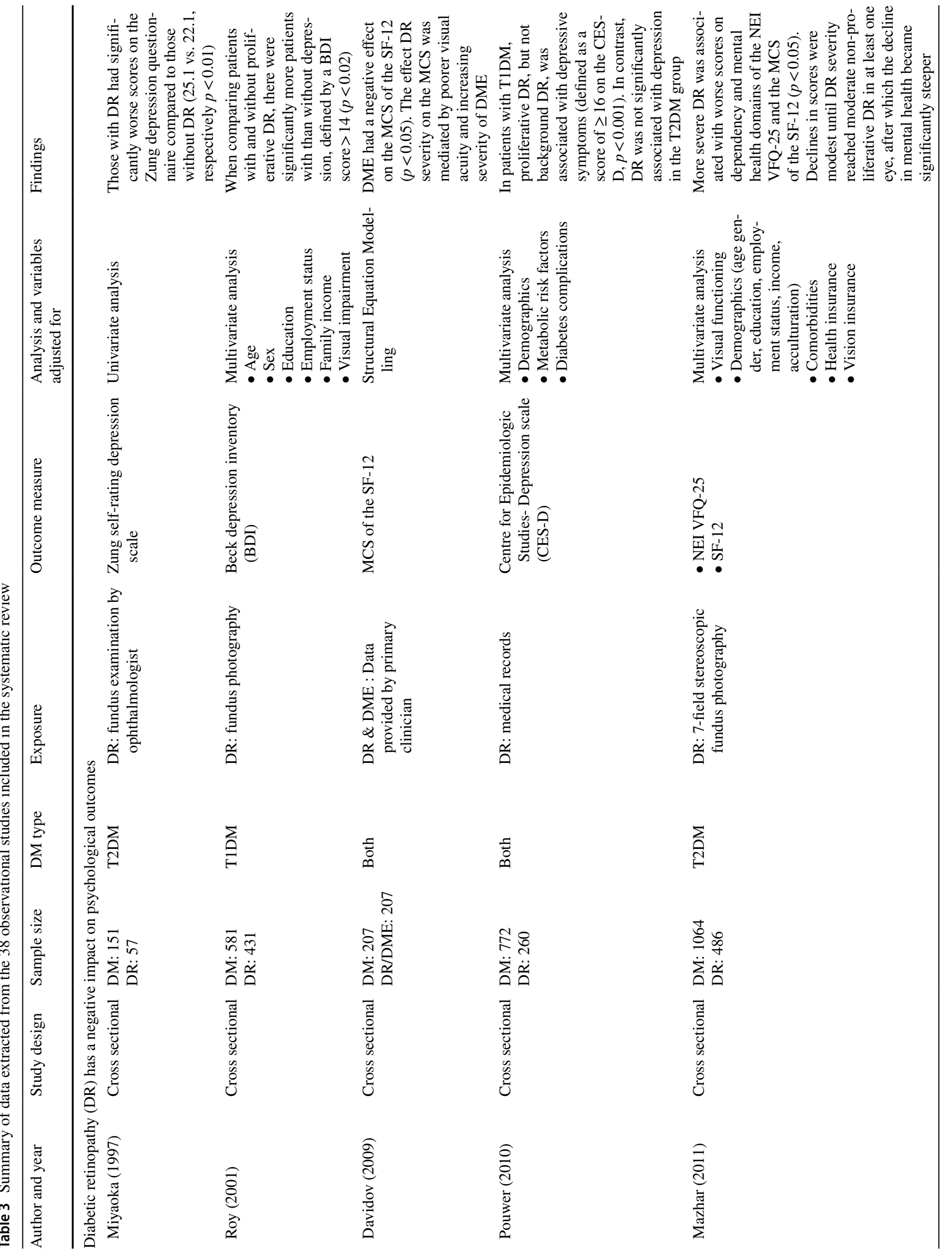




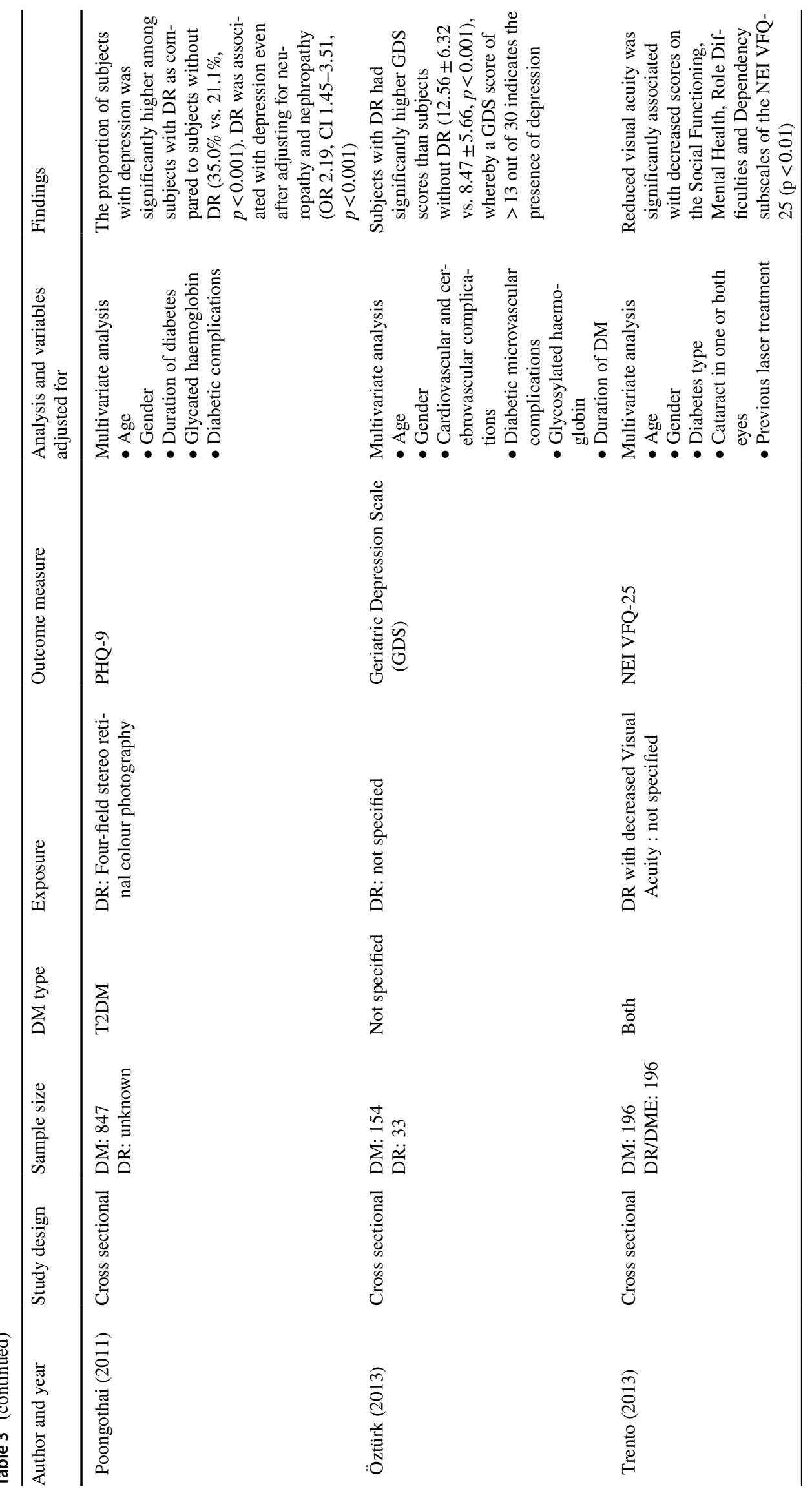




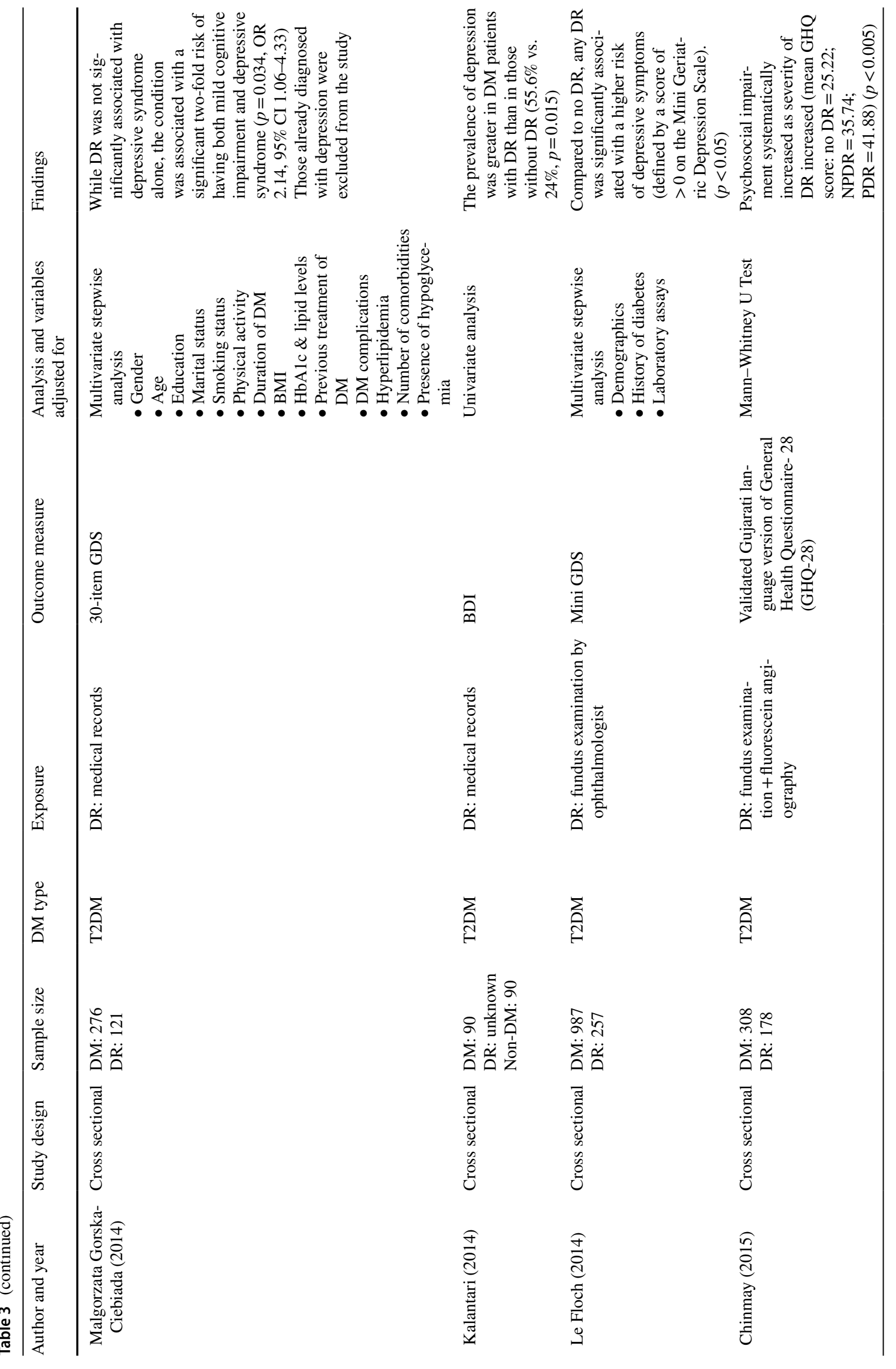




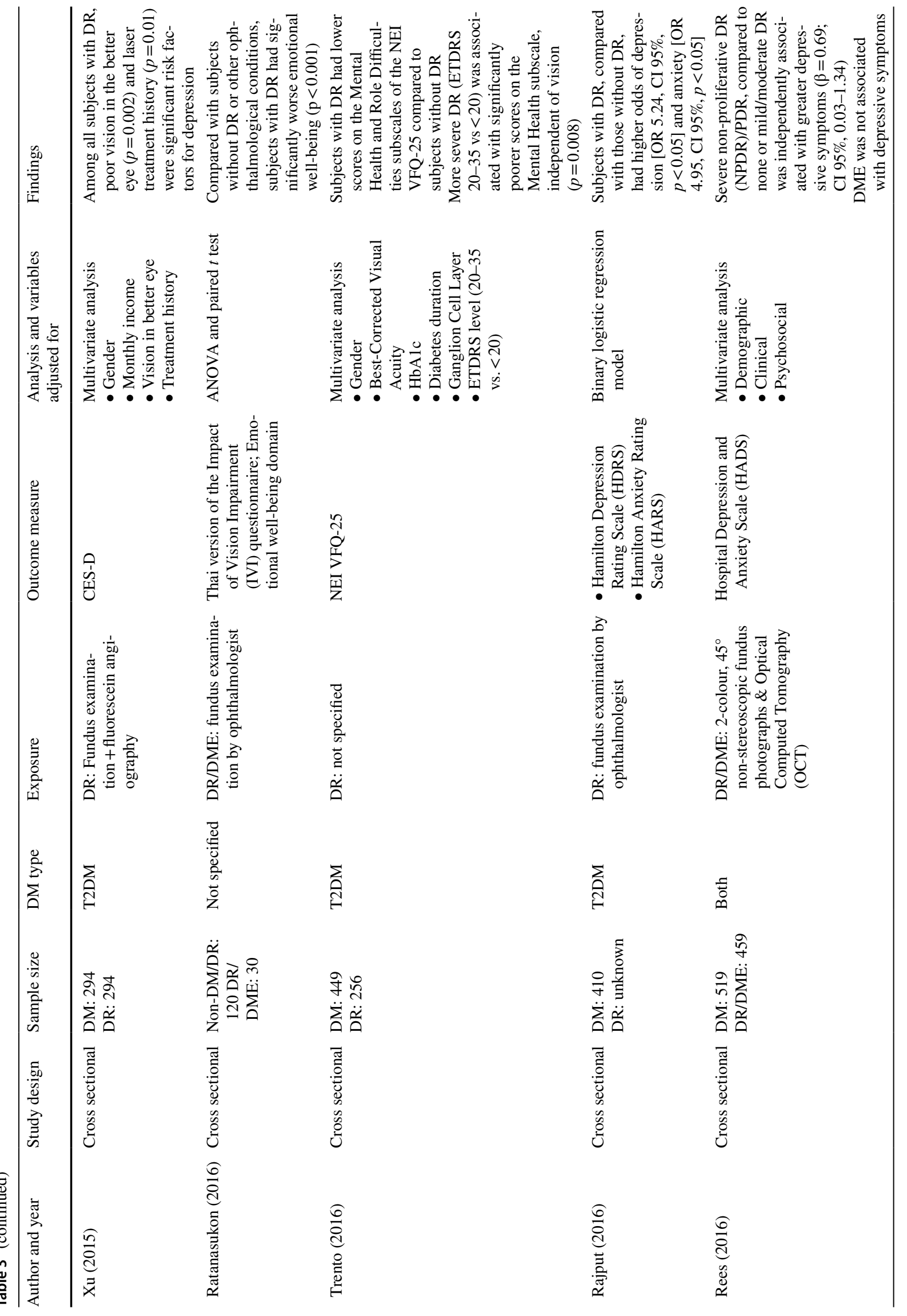




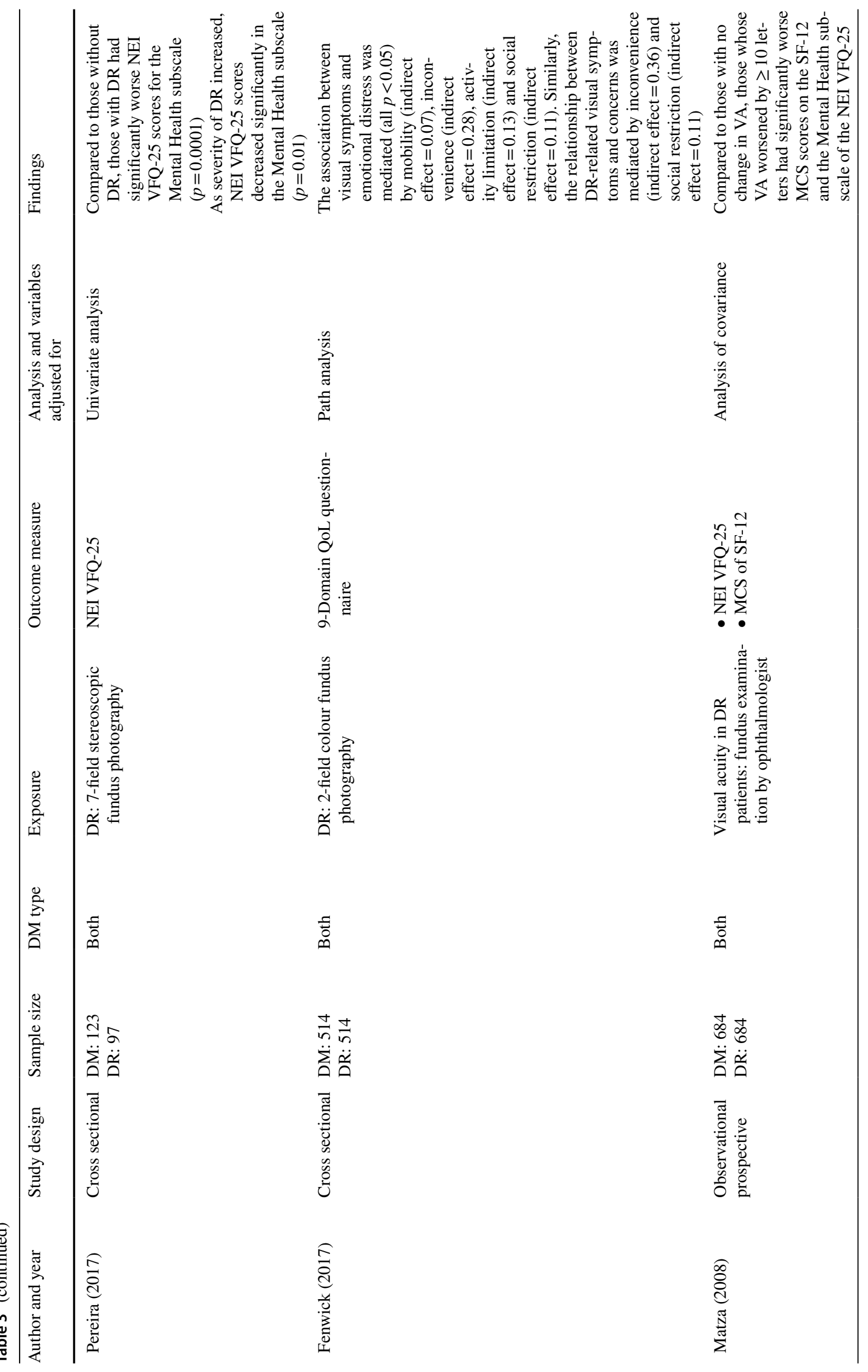




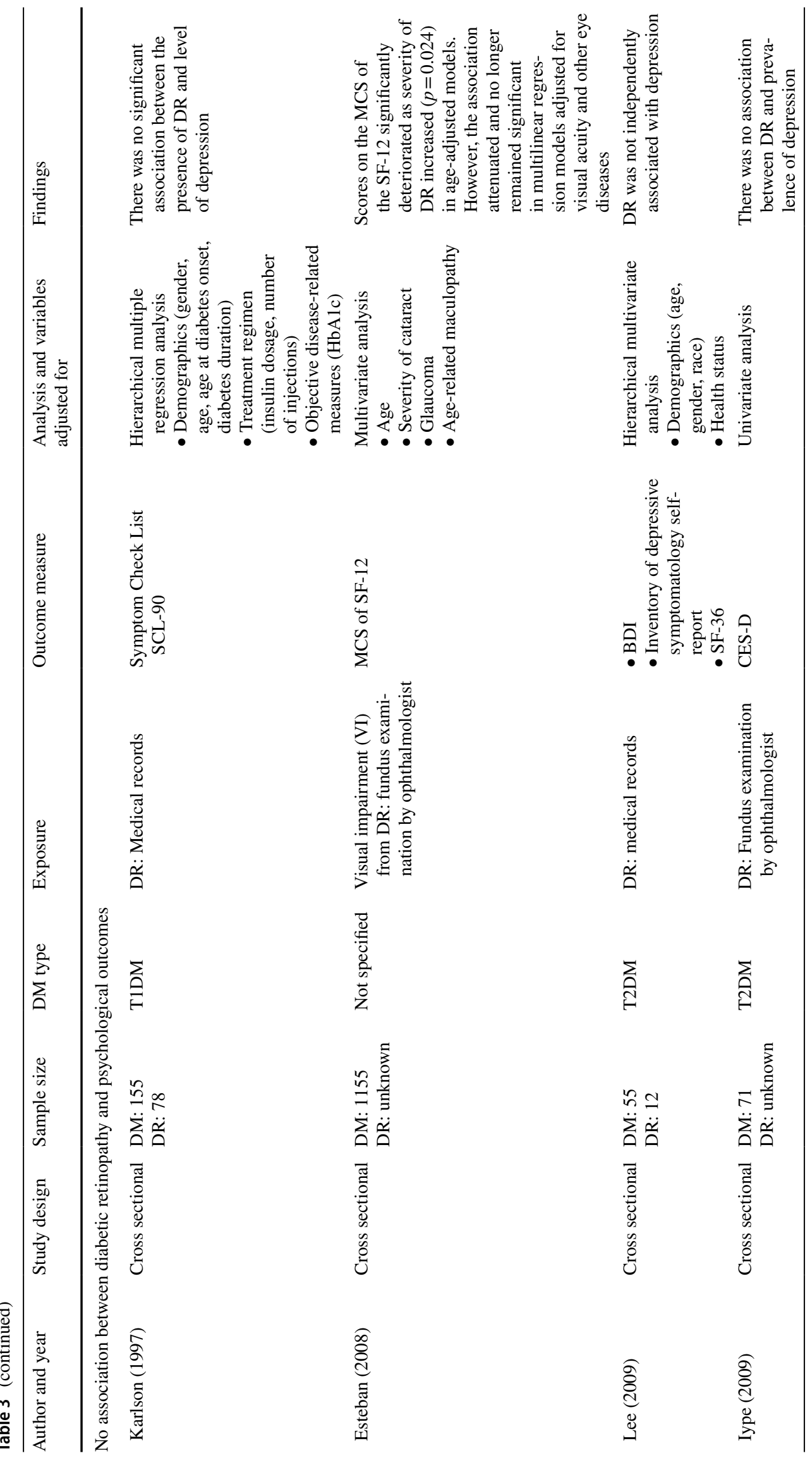




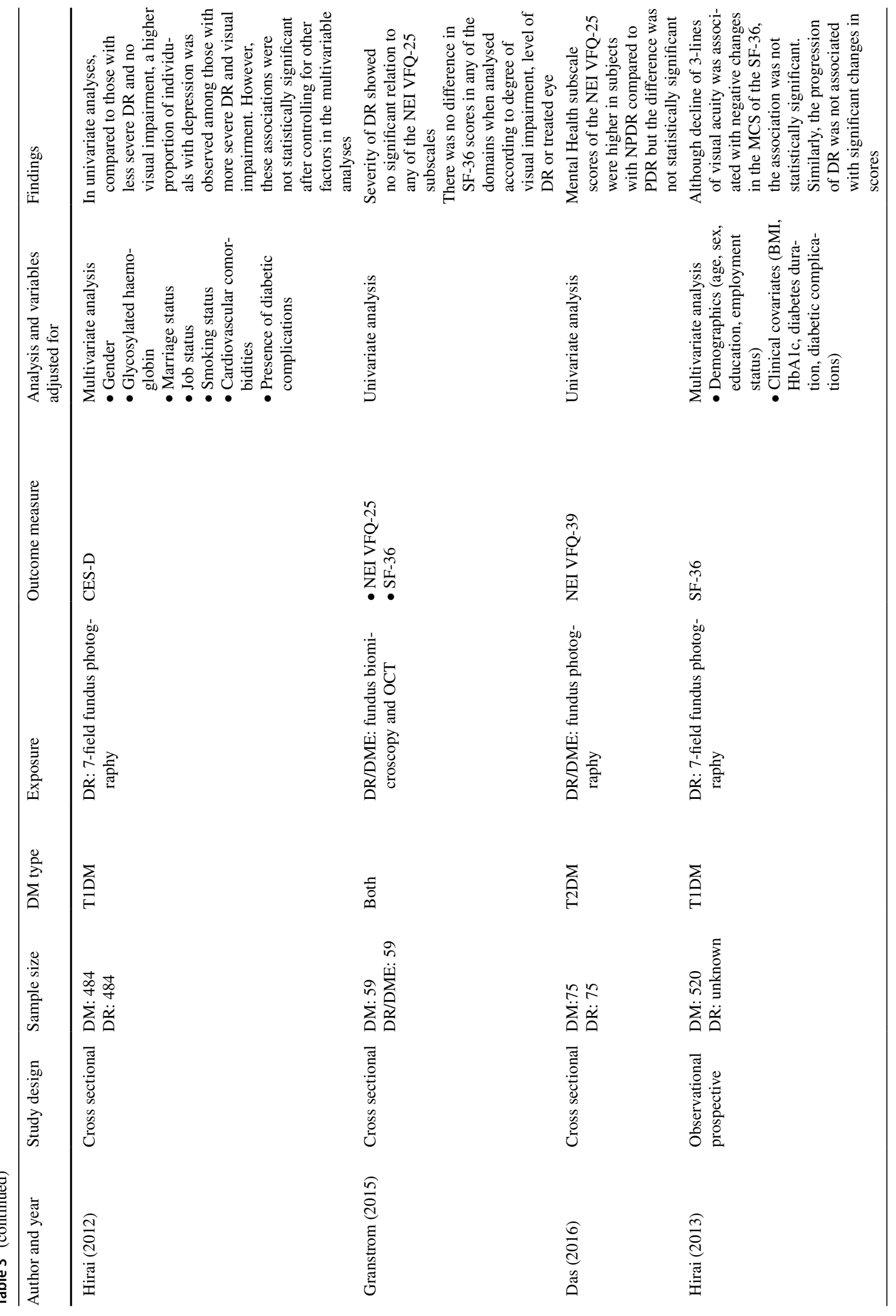




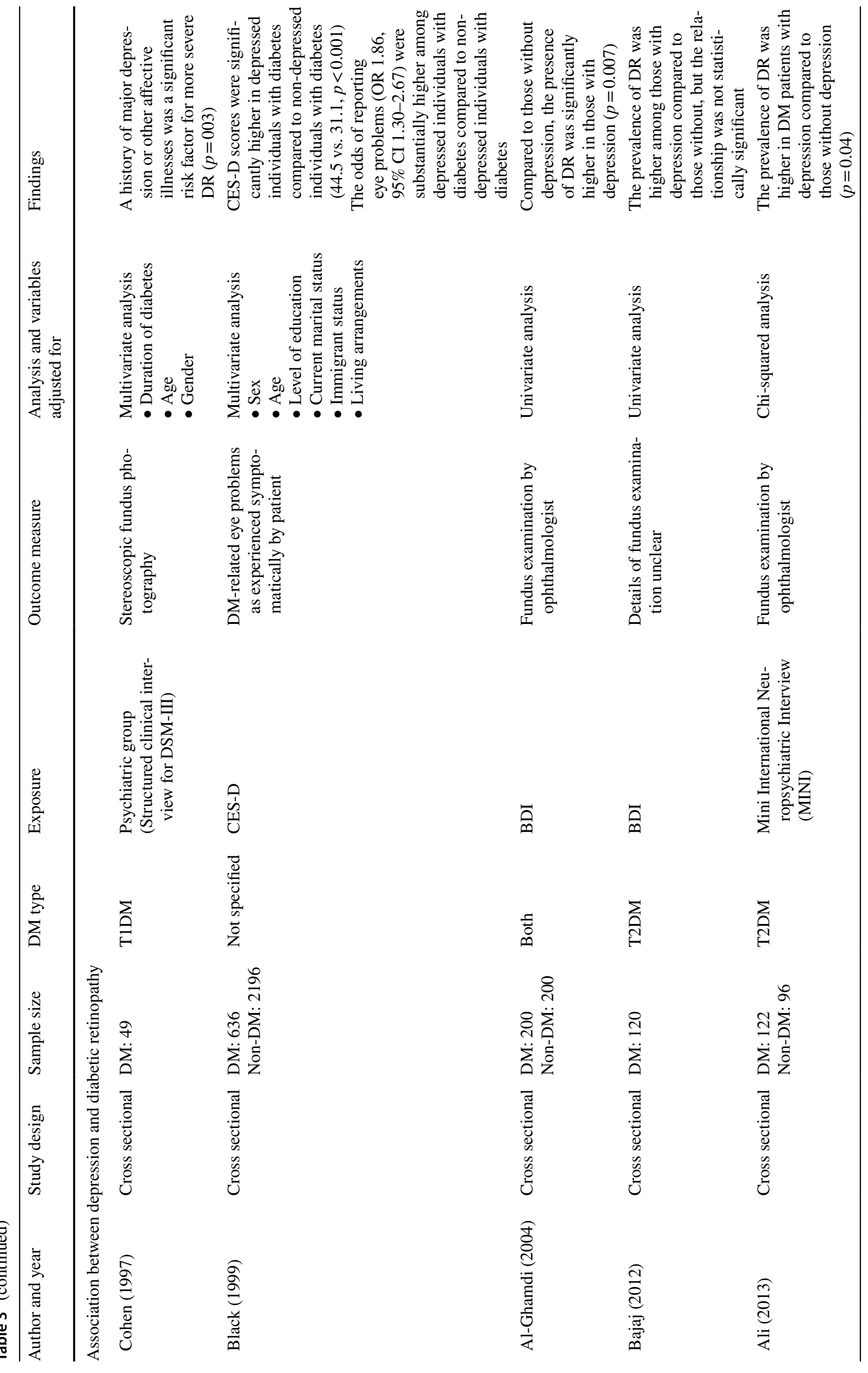




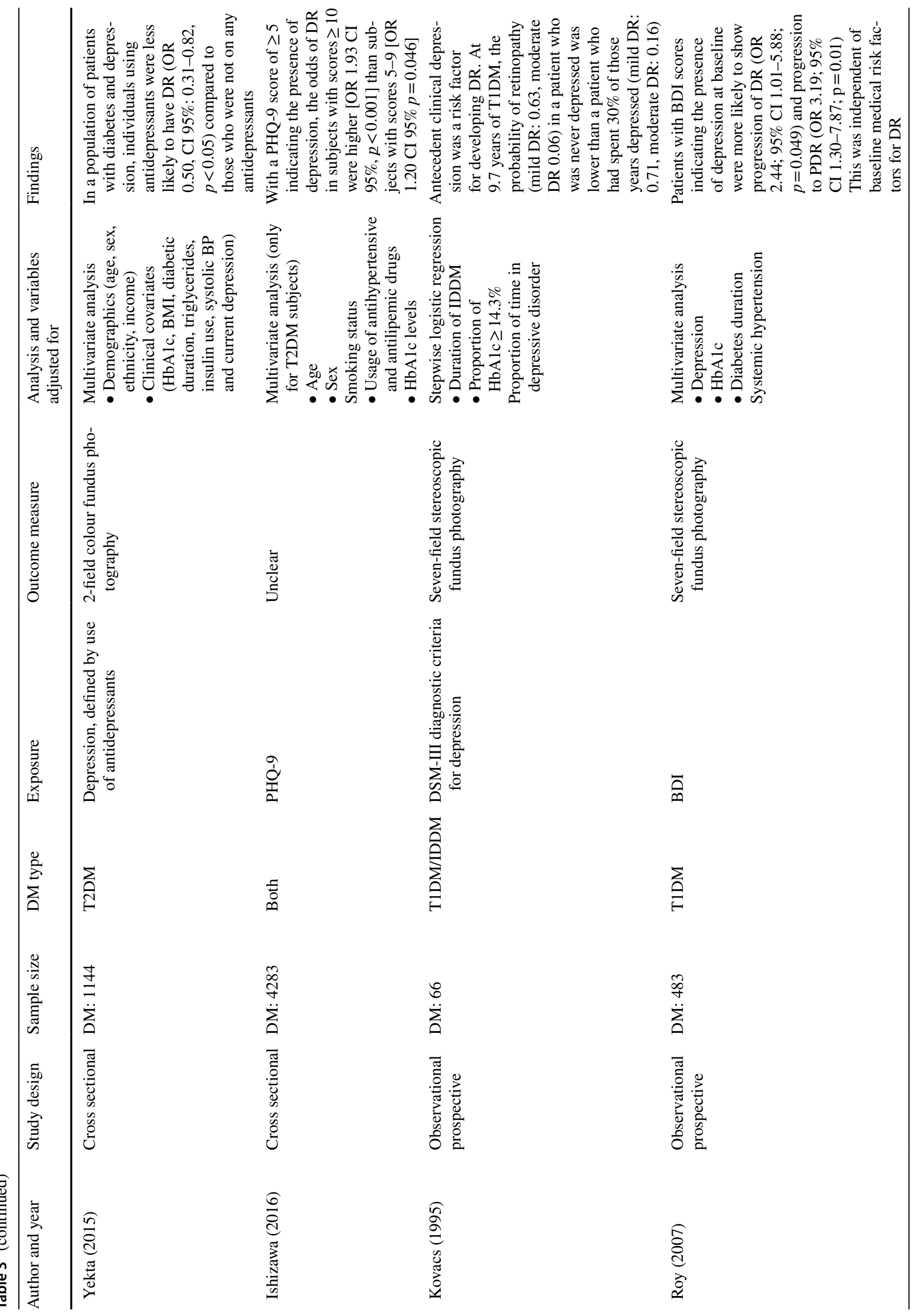




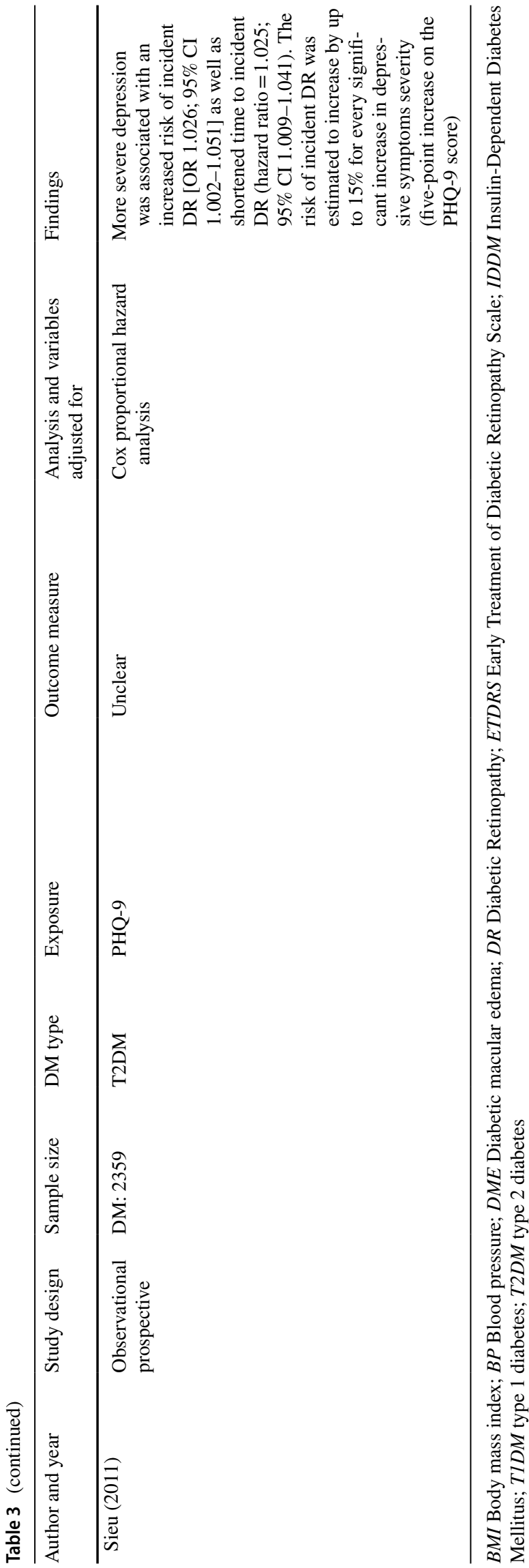

three other non-RCT studies assessing different treatment options for DR/DME [51-53].

\section{Sensitivity analysis}

After synthesising the results from 22 studies rated as "high quality" by either the NOS or the modified Downs and Black checklist, the findings remained similar to those of the full systematic review ( $n=42$ studies). In summary, DR was significantly associated with poor psychosocial functioning in 11 of 13 high-quality observational studies, [4, 9, 12-14, $28,29,32,54-56]$ with more severe DR was independently associated with worse psychosocial outcomes. Three cross-sectional studies did not find significant associations between DR and psychosocial functioning. Furthermore, the link between depressive symptoms and risk of DR remained, with three cross-sectional and two longitudinal high-quality studies showing that presence of depressive symptoms was associated with increased presence, incidence and progression of DR [15-18, 58].

\section{Discussion}

In this systematic review of the relationship between DR and psychosocial functioning, we found that DR/DME and related visual impairment, especially in more severe stages of DR, were significantly cross sectionally and longitudinally associated with poorer psychosocial outcomes, including higher levels of depression, anxiety and worse scores on mental health domains of health- and vision-related QoL questionnaires. Importantly, the relationship between depression and DR appears to be bi-directional, as the presence of depression or depressive symptoms is linked with incident, progression and severe DR. Our findings support the need for interventions to improve psychosocial wellbeing in patients with DR and also highlight the importance of prevention, early detection and management of depression in those with diabetes to reduce the development and progression of DR.

Our findings show that not only was DR-induced visual loss associated with poor mental health, but also DR alone was independently linked with worse psychosocial outcomes. This result suggests that factors beyond vision loss, such as contrast sensitivity, visual field loss and loss of colour and contrast may be important for mental health, [59-61] although studies specifically exploring this topic are lacking. Indeed, while visual impairment is important clinically, it only explains $30-40 \%$ of the variance in QoL in people with DR [62]. In addition, it is possible that loss of daily living activities and social life resulting from DR-related vision loss are responsible for declines in psychosocial well-being. As shown by Fenwick and colleagues, [14] the association 


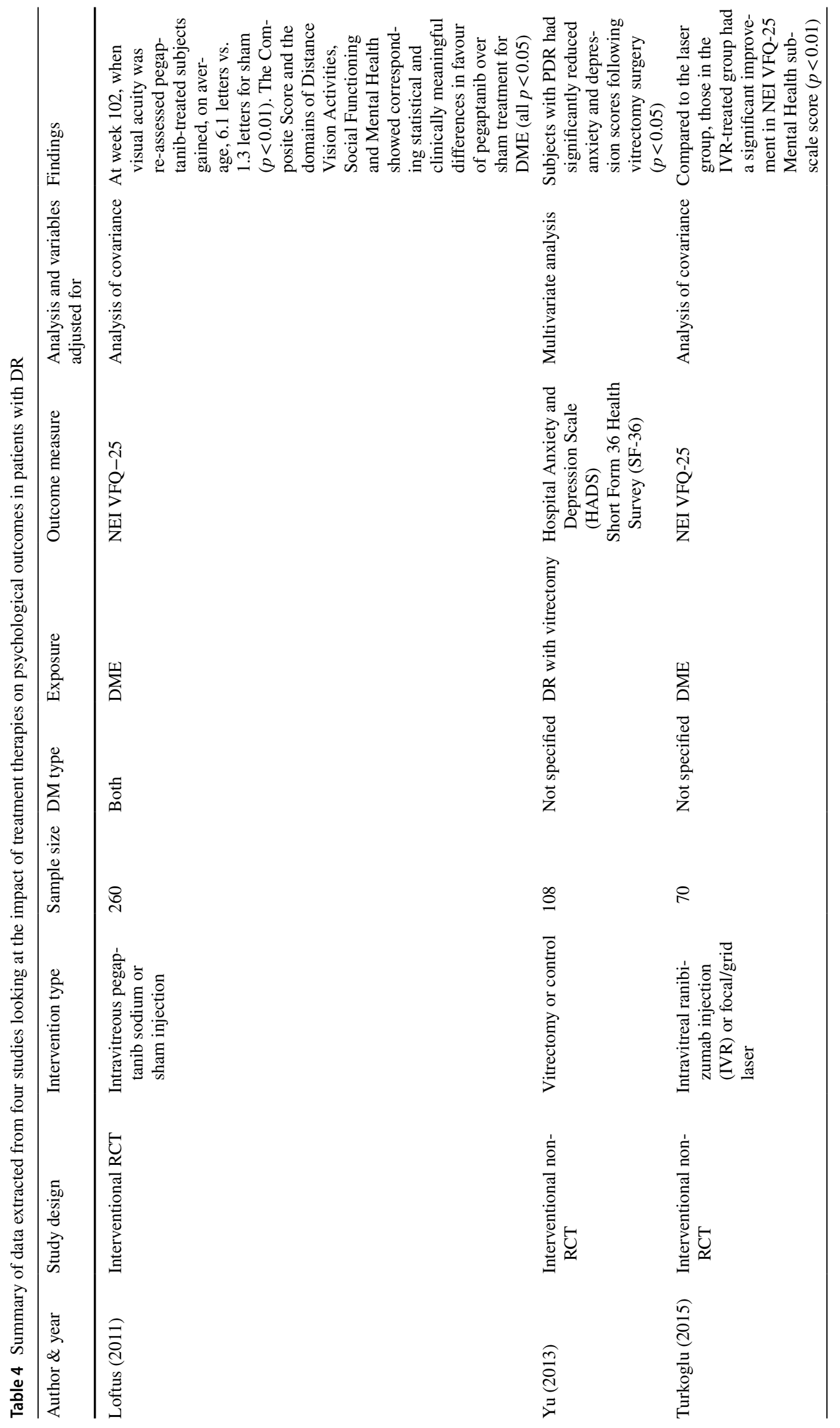




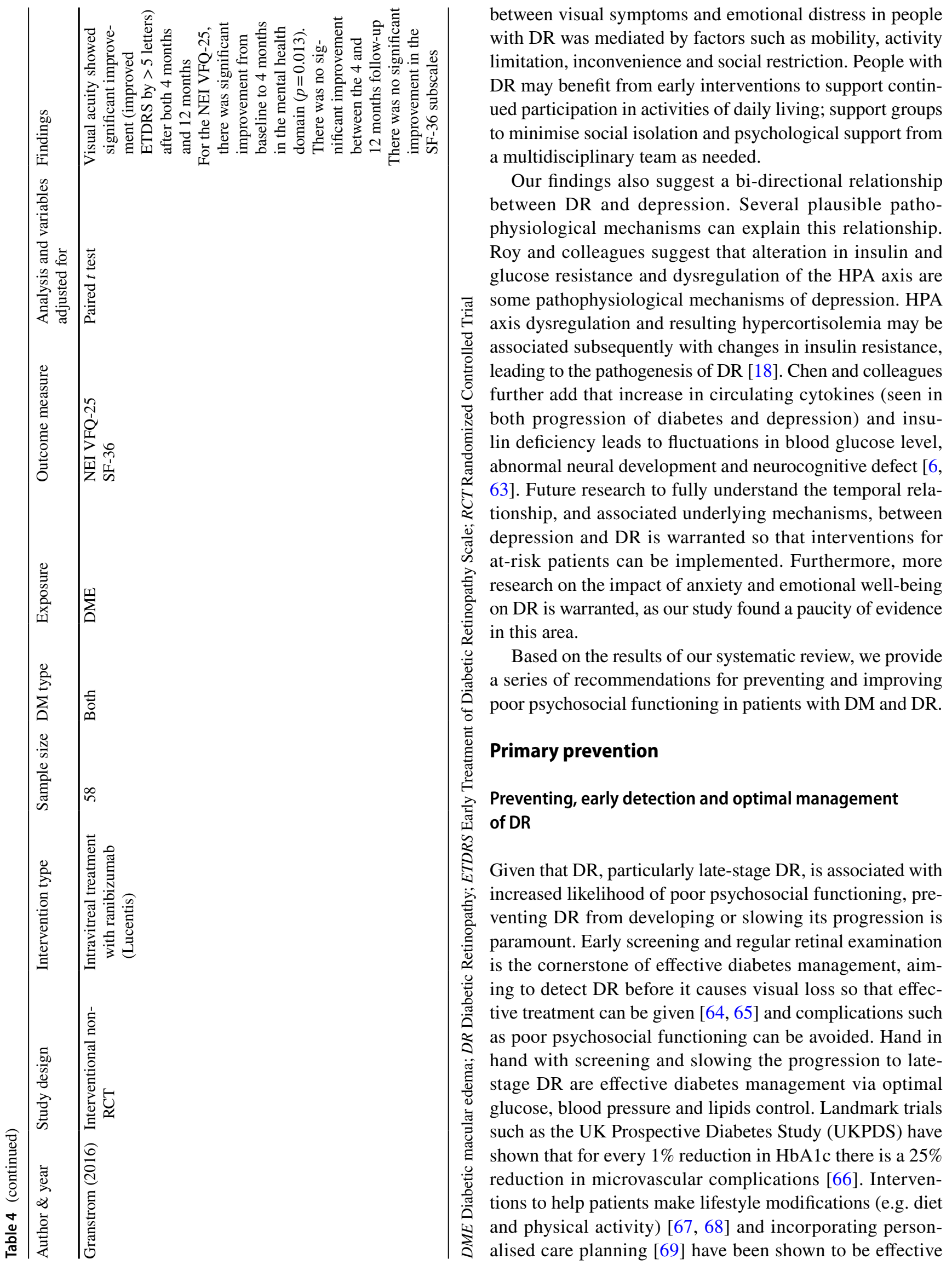


in improving diabetes control indicators and capability to self-manage their conditions, and implementation of such strategies to the broader diabetes population is needed.

\section{Improving the early detection and referral of poor psychosocial functioning in patients with DR}

Despite clear diagnostic guidelines for depression and the availability of good screening tools such as the PHQ-9, screening for depression is not routinely done for patients with DR during their clinic visits, resulting in a lack of timely detection and management [70]. A patient-reported outcome measure (PROM) tailored specifically to patients with DR would assist in the detection of poor mental health and inform subsequent referral pathways for continued care. RetCAT $[71,72]$ is an item bank and computerised adaptive testing (CAT) system comprising domains of DR-specific QoL including emotional well-being, social well-being and concerns. With an average of 7 items required to achieve precise measurement (e.g. standard error of measurement 0.387 [equivalent to 0.85 reliability]) of each emotional trait, RetCAT enables brief and yet robust measurement [71]. Ideally, RetCAT would be implemented in tertiary eye clinics allowing patients to take the surveys prior to consultation, with a report generated and stored in the patient's online medical records for discussion during the clinical consultation. Specific management strategies, including counselling, occupational therapy and vision rehabilitation, will be linked to the relevant RetCAT scores allowing patients to get the subsidiary care that they need. Moreover, with RetCAT performed at every visit, the patient's QoL status can be monitored over time. Evidence suggests that integration of PROMs in healthcare organisations, along with practitioner buy-in and support through education and training about the usefulness of such enterprises, can substantially improve patient care and physician-patient relationships [73].

\section{Secondary prevention}

\section{Improving the management of pre-existing depression in patients with diabetes}

Optimal management of depression through both medical and psychological therapy in patients with diabetes is essential to reduce the risk of patients developing DR. Integrated care which coordinates ophthalmologist and psychiatric/ psychological referrals, treatments and follow-up visits is likely to maximise efficiency and lead to effective patientcentred care [74].

a. The use of pharmacotherapy suggests that antidepressants can reduce depressive symptoms and slow the development of DR, possibly through control of the immunoinflammatory response, improved medication adherence and health behaviours leading to better diabetes control [6].

b. Evidence-based psychological strategies such as problem-solving therapy (PST) and Acceptance and Commitment Therapy (ACT) have been shown to be effective in reducing depressive symptoms in those with vision impairment [75] and DR and need to be considered [76].

A dedicated tool to determine the psychosocial impact of DR would be useful to inform management options. However, at present, most instruments rely on subscales in vision-related QoL tools like the IVI [77] and NEI VFQ [78] or even generic HRQOL tools such as the MCS of the SF instruments, which may not be sensitive to mental health outcomes specific to this condition. New instruments in development such as RetCAT [71] are needed to provide researchers, clinicians and rehabilitation workers with comprehensive and disease-specific tools to monitor and provide targeted interventions around mental health in people with DR.

Our systematic review has several strengths. First, most of the studies had sound methodological and study qualities, with more than half attaining high NOS scores. Second, our studies had wide geographic diversity, which aided in the generalisability of our results. We did not limit the timeframe, allowing a broad range of literature from 1988 to 2017. Last, we included studies with DR/psychosocial outcomes as both exposure and outcome, allowing to assess the potential for a bi-directional relationship.

However, we acknowledge certain limitations. The studies were largely cross sectional, with a handful of observational and interventional studies, and a lack of RCTs. Future longitudinal studies are warranted to more accurately assess the causality between DR and depression and to monitor disease progression. Given the potential for time-varying confounding, adjustments to properly estimate the relationship between DR and depression will be essential in subsequent longitudinal studies [79]. Another limitation was the lack of uniform measures to assess DR and its severity. While some studies used the ETDRS to categorise DR severity [80], others utilised ophthalmologist assessments or did not report the assessment method. This variation may have affected the comparability of studies. We included studies of all levels of quality in our review which could have reduced the robustness of our findings. However, when we conducted a sensitivity analysis including only those studies with a 'high-quality' rating, results were very similar. Finally, we were not able to conduct a meta-analysis due to the large number of outcomes and outcome measures considered in this review. Using a standardised, valid PROM for DR QoL such as RetCAT, subsequent pooling of data for comparison may be possible. 


\section{Conclusions}

Our systematic review found that DR/DME negatively affects psychosocial outcomes, reinforcing the need for primary physicians to continue targeting primary prevention of DR/DME and the importance of tight control of existing DR/ DME. Similarly, with depression as an independent risk factor for development and progression of DR/DME, this condition should be detected and treated early in patients with diabetes to reduce the incidence and progression of VTDR.

\section{Compliance with ethical standards}

Conflict of interest The authors declare that they have no conflicts of interest.

\section{References}

1. Lee, R., Wong, T. Y., \& Sabanayagam, C. (2015). Epidemiology of diabetic retinopathy, diabetic macular edema and related vision loss. Eye and Vision, 2, 17.

2. Yau, J. W., Rogers, S. L., Kawasaki, R., et al. (2012). Global prevalence and major risk factors of diabetic retinopathy. Diabetes Care, 35(3), 556-564.

3. Lamoureux, E. L., Shyong Tai, E., Thumboo, J., et al. (2010). Impact of diabetic retinopathy on vision-specific function. $O p h$ thalmology, 117(4), 757-765.

4. Davidov, E., Breitscheidel, L., Clouth, J., Reips, M., \& Happich, M. (2009). Diabetic retinopathy and health-related quality of life. Graefe's Archive for Clinical and Experimental Ophthalmology, 247(2), 267-272.

5. Fenwick, E., Rees, G., Pesudovs, K., et al. (2012). Social and emotional impact of diabetic retinopathy: A review. Clinical Experimental Ophthalmology, 40(1), 27-38.

6. Chen, X., \& Lu, L. (2016). Depression in diabetic retinopathy: A review and recommendation for psychiatric management. Psychosomatics, 57(5), 465-471.

7. Coyne, K. S., Margolis, M. K., Kennedy-Martin, T., et al. (2004). The impact of diabetic retinopathy: Perspectives from patient focus groups. Family Practice, 21(4), 447-453.

8. Chen, E., Looman, M., Laouri, M., et al. (2010). Burden of illness of diabetic macular edema: literature review. Current Medical Research and Opinion, 26(7), 1587-1597.

9. Rees, G., Xie, J., Fenwick, E. K., et al. (2016). Association between diabetes-related eye complications and symptoms of anxiety and depression. JAMA Ophthalmology., 134(9), 1007-1014.

10. de Groot, M. (2001). Association of Depression and diabetes complications: A meta-analysis. Psychosomatic Medicine, 63(4), 619-630.

11. Fenwick, E. K., Pesudovs, K., Rees, G., et al. (2011). The impact of diabetic retinopathy: understanding the patient's perspective. The British Journal of Ophthalmology., 95(6), 774-782.

12. Le Floch, J. P., Doucet, J., Bauduceau, B., \& Verny, C. (2014). Retinopathy, nephropathy, peripheral neuropathy and geriatric scale scores in elderly people with type 2 diabetes. Diabetic Medicine, 31(1), 107-111.

13. Trento, M., Durando, O., Lavecchia, S., et al. (2016) Vision related quality of life in patients with type 2 diabetes in the
EUROCONDOR trial. Endocrine. https://doi.org/10.1007/s1202 0-016-1097-0

14. Fenwick, E. K., Cheng, G. H., Man, R. E. K., et al. Interrelationship between visual symptoms, activity limitation and psychological functioning in patients with diabetic retinopathy. British Journal of Ophthalmology, 102(7), 948-953. 2017.

15. Yekta, Z., Xie, D., Bogner, H. R., et al. (2015). The association of antidepressant medications and diabetic retinopathy among people with diabetes. Journal of Diabetes and its Complications, 29(8), 1077-1084.

16. Ishizawa, K., Babazono, T., Horiba, Y., et al. (2016). The relationship between depressive symptoms and diabetic complications in elderly patients with diabetes: Analysis using the diabetes study from the Center of Tokyo Women's Medical University (DIACET). Journal of Diabetes and its Complications, 30(4), 597-602.

17. Black, S. A. (1999). Increased health burden associated with comorbid depression in older diabetic Mexican Americans. Results from the hispanic established population for the epidemiologic study of the elderly survey. Diabetes Care, 22(1), $56-64$.

18. Roy, M. S., Roy, A., \& Affouf, M. (2007). Depression is a risk factor for poor glycemic control and retinopathy in AfricanAmericans with type 1 diabetes. Psychosomatic Medicine, 69(6), 537-542.

19. Sieu, N., Katon, W., Lin, E. H., Russo, J., Ludman, E., \& Ciechanowski, P. (2011). Depression and incident diabetic retinopathy: A prospective cohort study. General Hospital Psychiatry, 33(5), 429-435.

20. Wild, S., Roglic, G., Green, A., Sicree, R., \& King, H. (2004). Global prevalence of diabetes: estimates for the year 2000 and projections for 2030. Diabetes Care, 27(5), 1047-1053.

21. Liberati, A., Altman, D. G., Tetzlaff, J., et al. (2009). The PRISMA statement for reporting systematic reviews and metaanalyses of studies that evaluate health care interventions: Explanation and elaboration. PLoS Medicine, 6(7), e1000100.

22. Deeks, J. J., Dinnes, J., D'Amico, R., et al. (2003). Evaluating non-randomised intervention studies. Health Technology Assessment (Winchester, England), 7(27), iii-x

23. Wong, M., Man, R., Gupta, P., Fenwick, E., Li, L. J., \& Lamoureux, E. (2017) A systematic review of the associations between dietary intake and diabetic retinopathy. Acta Ophthalmologica. https://doi.org/10.1111/j.1755-3768.2017.02312

24. Lo, C. K. L., Mertz, D., \& Loeb, M. (2014). Newcastle-Ottawa Scale: comparing reviewers' to authors' assessments. BMC Medical Research Methodology, 14, 45-45.

25. Downs, S. H., \& Black, N. (1998). The feasibility of creating a checklist for the assessment of the methodological quality both of randomised and non-randomised studies of health care interventions. Journal of Epidemiology and Community Health, 52(6), 377-384.

26. von Elm, E., Altman, D. G., Egger, M., Pocock, S. J., Gotzsche, P. C., \& Vandenbroucke, J. P. (2014). The Strengthening the reporting of observational studies in epidemiology (STROBE) statement: Guidelines for reporting observational studies. International Journal of Surgery (London, England), 12(12), 1495-1499.

27. Miyaoka, Y., Miyaoka, H., Motomiya, T., Kitamura, S., \& Asai, M. (1997). Impact of sociodemographic and diabetes-related characteristics on depressive state among non-insulin-dependent diabetic patients. Psychiatry and Clinical Neurosciences, 51(4), 203-206.

28. Poongothai, S., Anjana, R. M., Pradeepa, R., et al. (2011). Association of depression with complications of type 2 diabetes-the chennai urban rural epidemiology study (CURES-102). The Journal of the Association of Physicians of India, 59, 644-648. 
29. Öztürk, Z. A., Yeş il, Y., Kuyumcu, M. E., \& Kepekc,i, Y. (2013). Association of depression and sleep quality with complications of type 2 diabetes in elderly. European Geriatric Medicine, 4, S19.

30. Gorska-Ciebiada, M., Saryusz-Wolska, M., Ciebiada, M., \& Loba, J. (2014). Mild cognitive impairment and depressive symptoms in elderly patients with diabetes: Prevalence, risk factors, and comorbidity. Journal of Diabetes Research, 2014, 179648.

31. Kalantari, S., Jafarinezhad, A., \& Zohrevand, B. (2014). Association of depression with type 2 diabetes and relevant factors. Advanced Biomedical Research, 3, 244.

32. Xu, X., Zhao, X., Qian, D., Dong, Q., \& Gu, Z. (2015). Investigating factors associated with depression of type 2 diabetic retinopathy patients in China. PLoS ONE, 10(7), e0132616.

33. Ratanasukon, M., Tongsomboon, J., Bhurayanontachai, P., \& Jirarattanasopa, P. (2016). The impact of vision impairment (IVI) questionnaire; validation of the Thai-version and the implementation on vision-related quality of life in Thai rural community. PLOS ONE, 11(5), e0155509.

34. Rajput, R., Gehlawat, P., Gehlan, D., Gupta, R., \& Rajput, M. (2016). Prevalence and predictors of depression and anxiety in patients of diabetes mellitus in a tertiary care center. Indian Journal of Endocrinology and Metabolism, 20(6), 746-751.

35. Mazhar, K., Varma, R., Choudhury, F., McKean-Cowdin, R., Shtir, C. J., \& Azen, S. P. (2011). Severity of diabetic retinopathy and health-related quality of life: The Los Angeles Latino eye study. Ophthalmology, 118(4), 649-655.

36. Trento, M., Passera, P., Trevisan, M., et al. (2013). Quality of life, impaired vision and social role in people with diabetes: A multicenter observational study. Acta Diabetologica, 50(6), 873-877.

37. Matza, L. S., Rousculp, M. D., Malley, K., Boye, K. S., \& Oglesby, A. (2008). The longitudinal link between visual acuity and healthrelated quality of life in patients with diabetic retinopathy. Health and Quality of Life Outcomes, 6, 95.

38. Hirai, F. E., Tielsch, J. M., Klein, B. E., \& Klein, R. (2012). Relationship between retinopathy severity, visual impairment and depression in persons with long-term type 1 diabetes. Ophthalmic Epidemiology., 19(4), 196-203.

39. Granstrom, T., Forsman, H., Leksell, J., Jani, S., Raghib, A. M., \& Granstam, E. (2015). Visual functioning and health-related quality of life in diabetic patients about to undergo anti-vascular endothelial growth factor treatment for sight-threatening macular edema. Journal of Diabetes and its Complications, 29(8), 1183-1190.

40. Das, T., Wallang, B., Semwal, P., Basu, S., Padhi, T. R., \& Ali, M. H. (2016). Changing clinical presentation, current knowledgeattitude-practice, and current vision related quality of life in Selfreported type 2 diabetes patients with retinopathy in Eastern India: The LVPEI eye and diabetes study. Journal of Ophthalmology, 2016, 3423814.

41. Hirai, F. E., Tielsch, J. M., Klein, B. E., \& Klein, R. (2013). Tenyear change in self-rated quality of life in a type 1 diabetes population: Wisconsin epidemiologic study of diabetic retinopathy. Quality of Life Research, 22(6), 1245-1253.

42. Karlson, B., \& Agardh, C. D. (1997). Burden of illness, metabolic control, and complications in relation to depressive symptoms in IDDM patients. Diabetic Medicine, 14(12), 1066-1072.

43. Lee, H.-J., Chapa, D., Kao, C.-W., et al. (2009). Depression, quality of life, and glycemic control in individuals with type 2 diabetes. Journal of the American Academy of Nurse Practitioners, 21(4), 214-224.

44. Iype, T., Shaji, S. K., Balakrishnan, A., Charles, D., Varghese, A. A., \& Antony, T. P. (2009). Cognition in type 2 diabetes: Association with vascular risk factors, complications of diabetes and depression. Annals of Indian Academy of Neurology, 12(1), $25-27$.

45. Cohen, S. T., Welch, G., Jacobson, A. M., De Groot, M., \& Samson, J. (1997). The Association of lifetime psychiatric illness and increased retinopathy in patients with type I diabetes mellitus. Psychosomatics, 38(2), 98-108.

46. Al-Ghamdi, A. A. (2004). A high prevalence of depression among diabetic patients at a teaching hospital in Western Saudi Arabia. Neurosciences (Riyadh, Saudi Arabia), 9(2), 108-112.

47. Ali, N., Jyotsna, V. P., Kumar, N., \& Mani, K. (2013). Prevalence of depression among type 2 diabetes compared to healthy non diabetic controls. The Journal of the Association of Physicians of India, 61(9), 619-621.

48. Kovacs, M., Mukerji, P., Drash, A., \& Iyengar, S. (1995). Biomedical and psychiatric risk factors for retinopathy among children with IDDM. Diabetes Care, 18(12), 1592-1599.

49. Bajaj, S., Agarwal, S. K., Varma, A., \& Singh, V. K. (2012). Association of depression and its relation with complications in newly diagnosed type 2 diabetes. Indian Journal of Endocrinology and Metabolism, 16(5), 759-763.

50. Loftus, J., Sultan, M., \& Pleil, A. (2011). Changes in vision- and health-related quality of life in patients with diabetic macular edema treated with pegapactanib sodium or sham. Investigative Ophthalmology \& Visual Science, 52(10), 7498-7505.

51. Turkoglu, E. B., Celik, E., Aksoy, N., Bursali, O., Ucak, T., \& Alagoz, G. (2015). Changes in vision related quality of life in patients with diabetic macular edema: Ranibizumab or laser treatment? Journal of Diabetes and its Complications, 29(4), 540-543.

52. Granstrom, T., Forsman, H., Lindholm Olinder, A., et al. (2016). Patient-reported outcomes and visual acuity after 12 months of anti-VEGF-treatment for sight-threatening diabetic macular edema in a real world setting. Diabetes Research and Clinical Practice, 121, 157-165.

53. Yu, Y., Feng, L., Shao, Y., et al. (2013). Quality of life and emotional change for middle-aged and elderly patients with diabetic retinopathy. International Journal of Ophthalmology, 6(1), 71-74.

54. Roy, A., \& Roy, M. (2001). Depressive symptoms in AfricanAmerican type 1 diabetics. Depression and Anxiety, 13(1), 28-31.

55. Pouwer, F., Geelhoed-Duijvestijn, P. H. L. M., Tack, C. J., et al. (2010). Prevalence of comorbid depression is high in out-patients with Type 1 or Type 2 diabetes mellitus. Results from three outpatient clinics in the Netherlands. Diabetic Medicine, 27(2), 217-224.

56. Mazhar, K., Varma, R., Choudhury, F., et al. (2011). Severity of diabetic retinopathy and health-related quality of life: The Los Angeles Latino eye study. Ophthalmology, 118(4), 649-655.

57. Esteban, J. J. N., Martínez, M. S., Navalón, P. G., et al. (2008). Visual impairment and quality of life: gender differences in the elderly in Cuenca, Spain. Quality of Life Research, 17(1), 37-45.

58. Sieu, N., Katon, W., Lin, E. H. B., Russo, J., Ludman, E., \& Ciechanowski, P. (2011). Depression and incident diabetic retinopathy: A prospective cohort study. General Hospital Psychiatry., 33(5), 429-435.

59. Mantyjarvi, M. (1989). Colour vision and dark adaptation in diabetic patients after photocoagulation. Acta Ophthalmologica, 67(2), 113-118.

60. dos Santos, N. A., \& Andrade, S. M. (2012). Visual contrast sensitivity in patients with impairment of functional independence after stroke. BMC Neurology, 12, 90-90.

61. Gall, C., Brosel, D., \& Sabel, B. A. (2013). Remaining visual field and preserved subjective visual functioning prevent mental distress in patients with visual field defects. Frontiers in Human Neuroscience, 7, 584.

62. Lamoureux, E. L., Hassell, J. B., \& Keeffe, J. E. (2004). The determinants of participation in activities of daily living in people with impaired vision. American Journal of Ophthalmology, 137(2), 265-270.

63. Korczak, D. J., Pereira, S., Koulajian, K., Matejcek, A., \& Giacca, A. (2011). Type 1 diabetes mellitus and major depressive disorder: Evidence for a biological link. Diabetologia, 54(10), 2483. 
64. Jones, C. D., Greenwood, R. H., Misra, A., \& Bachmann, M. O. (2012). Incidence and progression of diabetic retinopathy during 17 years of a population-based screening program in England. Diabetes Care, 35(3), 592-596.

65. Scanlon, P. H. (2008). The English national screening programme for sight-threatening diabetic retinopathy. Journal of Medical Screening, 15(1), 1-4.

66. Intensive blood-glucose. (1998). control with sulphonylureas or insulin compared with conventional treatment and risk of complications in patients with type 2 diabetes (UKPDS 33). UK prospective diabetes study (UKPDS) group. Lancet, 352(9131), 837-853.

67. Seib, C., Parkinson, J., McDonald, N., Fujihira, H., Zietek, S., \& Anderson, D. (2018). Lifestyle interventions for improving health and health behaviours in women with type 2 diabetes: A systematic review of the literature 2011-2017. Maturitas, 111, 1-14.

68. Sleiman, D., Al-Badri, M. R., \& Azar, S. T. (2015). Effect of mediterranean diet in diabetes control and cardiovascular risk modification: A systematic review. Frontiers in Public Health, 3, 69.

69. Coulter, A., Entwistle, V. A., Eccles, A., Ryan, S., Shepperd, S., \& Perera, R. (2015) Personalised care planning for adults with chronic or long-term health conditions. The Cochrane Database of Systematic Reviews (3):Cd010523. https://doi.org/10.1002/14651 858

70. Holloway, E. E., Sturrock, B. A., Lamoureux, E. L., Keeffe, J. E., \& Rees, G. (2015). Depression screening among older adults attending low-vision rehabilitation and eye-care services: Characteristics of those who screen positive and client acceptability of screening. Australasian Journal on Ageing, 34(4), 229-234.

71. Fenwick, E., Khadka, J., Pesudovs, K., Rees, G., \& Lamoureux, E. (2017) Diabetic retinopathy and macular edema quality-of-life item banks: Development and initial evaluation using computerized adaptive testing. Investigative Ophthalmology \& Visual Science, 58(14), 6379-6387. https://doi.org/10.1167/iovs.16-20950.

72. Fenwick, E. K., Pesudovs, K., Khadka, J., Rees, G., Wong, T. Y., \& Lamoureux, E. L. (2013). Evaluation of item candidates for a diabetic retinopathy quality of life item bank. Quality Life Research, 22(7), 1851-1858.

73. Rotenstein, L. S., Huckman, R. S., \& Wagle, N. W. (2017). Making patients and doctors happier - the potential of patient-reported outcomes. The New England Journal of Medicine, 377(14), 1309-1312.
74. Patel, V., \& Chatterji, S. (2015). Integrating mental health in care for noncommunicable diseases: An imperative for person-centered care. Health Affairs, 34(9), 1498-1505.

75. Holloway, E. E., Xie, J., Sturrock, B. A., Lamoureux, E. L., \& Rees, G. (2015). Do problem-solving interventions improve psychosocial outcomes in vision impaired adults: A systematic review and meta-analysis. Patient Education and Counseling, 98(5), 553-564.

76. Rees, G., O'Hare, F., Saeed, M., et al. (2017). Problem-solving therapy for adults with diabetic retinopathy and diabetes-specific distress: A pilot randomized controlled trial. BMJ Open Diabetes Research \& Care, 5(1), e000307.

77. Lamoureux, E. L., Pallant, J. F., Pesudovs, K., Rees, G., Hassell, J. B., \& Keeffe, J. E. (2007). The impact of vision impairment questionnaire: An Assessment of Its domain structure using confirmatory factor analysis and rasch analysis. Investigative Ophthalmology \& Visual Science, 48(3), 1001-1006.

78. Orr, P., Rentz, A. M., Margolis, M. K., et al. (2011). Validation of the National Eye Institute Visual Function Questionnaire-25 (NEI VFQ-25) in age-related macular degeneration. Investigative Ophthalmology Visual Science, 52(6), 3354-3359.

79. Mansournia, M. A., Etminan, M., Danaei, G., Kaufman, J. S., \& Collins, G. (2017). Handling time varying confounding in observational research. $B M J, 359, \mathrm{j} 4587$.

80. Grading diabetic retinopathy. (1991). from stereoscopic color fundus photographs-an extension of the modified airlie house classification. ETDRS report number 10. Early treatment diabetic retinopathy study research group. Ophthalmology, 98 (5 Suppl), 786-806.

81. Fenwick, E. K., Pesudovs, K., Khadka, J., Dirani, M., Rees, G., Wong, T. Y., Lamoureux, E. L. (2012). The impact of diabetic retinopathy on quality of life: Qualitative findings from an item bankdevelopment project. Quality of Life Research, 21(10), 1771-1782.

Publisher's Note Springer Nature remains neutral with regard to jurisdictional claims in published maps and institutional affiliations. 